\title{
ESCOLA SEM PARTIDO NA AGENDA EDUCACIONAL DO GOVERNO \\ BOLSONARO
}

RESUMO: A eleição de Bolsonaro, aliado histórico do movimento Escola sem Partido (ESP), abriu espaço para novas pautas na agenda educacional. Tal abertura poderia significar o alçar do ESP e de suas pautas às decisões governamentais. O presente artigo busca evidenciar se o ESP tem papel relevante na construção da agenda educacional do governo Bolsonaro. A metodologia se dará por análises de reportagens, publicações nas redes sociais digitais de atores envolvidos e documentos oficiais. Como resultado, percebe-se a pouca relevância do ESP na delimitação da agenda, apesar da adoção de suas pautas pelo governo.

Palavras-chave: Escola sem Partido; Agenda Educacional; Governo Bolsonaro.

\section{ESCOLA SEM PARTIDO IN THE BOLSONARO GOVERNMENT'S EDUCATIONAL AGENDA}

\begin{abstract}
Bolsonaro's election, a historic ally of the Escola sem Partido (ESP) movement, opened space for new demands in the educational agenda. Such an opening could mean the rise of ESP and its guidelines to government decisions. This article seeks to show if ESP has a relevant role in the construction of the Bolsonaro government's educational agenda. The methodology will be based on analyzes analysis of news reports, publications on the digital social networks of actors involved and official documents. As a result, there is little relevance for ESP in defining the agenda, despite the government's adoption of its guidelines.
\end{abstract}

Keywords: Escola sem Partido; Educational Agenda; Bolsonaro’s Government.

\section{INTRODUÇÃO}

O movimento Escola sem Partido (ESP), criado em 2004 pelo advogado e procurador aposentado Miguel Nagib, se define como "iniciativa conjunta de estudantes e pais preocupados com o grau de contaminação político-ideológica das escolas brasileiras, em todos os níveis: do ensino básico ao superior" (ESCOLA SEM PARTIDO, 2019c). Para o ESP, os sistemas escolares nacionais foram cooptados por forças à

\footnotetext{
${ }^{1}$ Doutorando em Educação pelo Programa de Pós-Graduação em Educação da Universidade Federal de Minas Gerais (UFMG). E-mail: 1ucasfelicetti@gmail.com 
esquerda no espectro político e os professores, militantes disfarçados, doutrinam os alunos com concepções de mundo que destoam da tradicional/cristã/capitalista.

Ao longo dos anos, o ESP atrelou outras pautas à mobilização contrária à ideologia no meio escolar, como a defesa de valores liberais e o combate ao trato de questões de gênero e sexualidade. Essa adoção a novas frentes de atuação possibilitou a articulação do ESP com diversos atores políticos, econômicos e religiosos e aumentou sua capilaridade e ressonância no cenário das políticas educativas nacionais (MIGUEL, 2016). Dentre essas articulações estão o então deputado, e atual presidente, Jair Bolsonaro e seus filhos políticos. A pedido da família Bolsonaro, em 2014, Miguel Nagib redigiu o primeiro Projeto de Lei (PL) sobre o "Programa Escola sem Partido", que se tornou modelo para inúmeros outros em território nacional (MACHADO, 2018). E Jair Bolsonaro, antiga referência na luta contra a "ideologia de gênero", defendeu em suas propostas de governo para eleição presidencial de 2018 um ensino "sem doutrinação e sexualização precoce" (BOLSONARO, 2018, p. 41).

Tendo como partida este contexto de imbricações entre o movimento e o clã presidencial, o artigo busca evidenciar se o ESP tem papel relevante na construção da agenda governamental de políticas de educação do governo Bolsonaro. Para tal, nos basearemos no modelo de formação de agenda de Kingdon (2014), em especial a partir de suas proposições relativas ao fluxo da dimensão política. A ênfase nesse fluxo se justifica pelas colocações a respeito do humor nacional (national mood) - que pode se relacionar ao pânico social moral causado pelos temores da "ideologia de gênero" (MISKOLCI; CAMPANA, 2017) - e da mudança de governo (turnouver) - com a possibilidade, ou não, de mudanças na ação governamental devido à nova gestão. A metodologia se constituirá por análise de reportagens, publicações nas redes sociais digitais do ESP, Miguel Nagib família Bolsonaro, Ministério da Educação e seus ministros neste governo, além de pesquisas em documentos oficiais sobre as políticas de educação e sites institucionais.

\section{A AGENDA E SUA FORMAÇÃO}


John Kingdon (2014) é um importante cientista político estadunidense cujo trabalho é referência para estudos que levam em conta os processos formativos de políticas públicas. Em seu livro Agendas, Alternatives, and Public Policies, Kingdon traz foco para como alguma determinada demanda política passa a figurar na agenda de governo e como, de forma ampla, é constituída essa agenda. Seu modelo teórico que explica a formação da agenda a partir da confluência de diversas ações, atores, contextos e interesses em três tipos de fluxos distintos: problemas (problems); soluções/alternativas (policies) e; político (politics). Nesta seção abordaremos os fluxos, em especial o político, conceitos e os atores envolvidos.

Antes de adentrar nas explanações sobre os três fluxos, é necessário ressaltar como o autor conceitua "agenda" e quais são os atores envolvidos nesses processos. De forma geral, Kingdon entende "agenda" como um conjunto de assuntos ou problemas que recebem grande atenção por parte de membros do governo e atores próximos a estes em um determinado momento. Com relação aos atores, enquanto membros do governo, ele destaca o relevante papel do presidente, que tem o maior poder institucional de formar agenda e vocalizar suas demandas. Sua capacidade de veto de atos legislativos e abaixo na hierarquia governamental, somada às de admitir e demitir atores do governo refletem seu poderio na determinação da agenda. Contudo o presidente não tem o controle total sobre a consideração da possível entrada de demandas e alternativas na agenda, o que dá espaço para a atuação do corpo institucional por ele definido. Mesmo que os agentes indicados, como ministros, por exemplo, não sejam criadores das ideias/demandas, mas endossando-as faz com que ganhem proeminência na formação da agenda, dada a relevância de seus cargos e proximidade com o presidente.

Grupos envolvidos com o mercado, instituições profissionais e corporativas, assim como o interesse público nacional representam forças externas ao governo, que têm seu peso nos processos de formulação da agenda. A simples pressão destes por alguma pauta específica não induz, necessariamente, a uma consideração por parte do governo. O interesse governamental na demanda, os recursos disponíveis pelo proponente, a possibilidade de impacto positivo na economia, em eleições e a coesão do grupo de interesse na defesa de suas propostas são pontos favoráveis, mas não garantidores, para a consideração destas pelo governo para entrada na agenda. 
A mobilização destes atores em prol da ascensão de suas demandas na agenda pode ser propositiva pelo entrelace de dimensões específicas do processo de formulação da agenda. O fluxo de problemas é etapa em que certas condições permeadas por determinadas particularidades e inseridas em um contexto específico se tornam favoráveis à apreciação do poder público. Tais condições tornam-se problemas que merecem a atenção e ação de formuladores de políticas, segundo a interpretação destes. A existência de indicadores (dados, informações) que favoreçam uma determinada interpretação, a ocorrência de crises ou eventos específicos e uma cobrança por prestação de contas das ações governamentais reforçam a possibilidade do reconhecimento de uma condição enquanto problema, mas não há garantia dessa reconfiguração interpretativa.

O fluxo de soluções/alternativas se dá pela necessidade dos formuladores de políticas em buscar soluções viáveis e disponíveis para os problemas já reconhecidos. Muitas soluções e alternativas emergem nesse momento, mas as de menor custo e que tem um melhor reconhecimento e aprovação pública se destacam para uma possível consideração por parte do poder decisório. Tal processo é permeado pela intensa difusão das alternativas em embate nas chamadas comunidades políticas, em busca de uma aprovação consensual.

O fluxo político, tido como o mais importante para a emergência de uma demanda à agenda, se caracteriza pela construção de coalizões baseadas em trocas e negociações (CAPELLA, 2005). A emergência de uma determinada pauta à agenda depende da correlação de forças e barganhas intrínsecas a fenômenos e processos desse fluxo, como o humor nacional, campanha de grupos de pressão, resultados eleitorais, distribuição ideológica e partidária no congresso e mudanças na administração governamental.

O humor nacional, ou clima nacional, é referente à percepção de integrantes do governo sobre a constância, preponderância e compartilhamento de alguma ideia, sentimento ou perspectiva no contexto político nacional em um determinado período de tempo. Não equivalente à opinião pública, a subjetividade do humor nacional pode ser percebida de duas formas: pelos governantes eleitos, a partir de suas percepções sobre o humor político preponderante em suas reuniões, e-mails, diálogos com suas bases, coletivos e indivíduos; e pelos membros não eleitos do governo, por meio de conversas com os próprios políticos. A percepção de mudança no clima nacional é essencial para viabilizar propostas de políticas e fazê-las ascender à agenda, assim como indicam a 
necessidade de recrudescimento de certas iniciativas, como um "solo fértil" para a "plantação" de certas ideias, e nem tanto para outras, dado ao "clima" vigente.

A pressão exercida por grupos não governamentais organizados é catalisada, como mencionado em relação aos atores externos ao governo, quando seus interesses são sustentados por grandes quantidades de recursos políticos e financeiros. Recursos fortalecem a participação de grupos específicos como apoio em processos eleitorais, por exemplo. Assim, o endossamento a certos postulantes ao governo, se vitoriosos, pode favorecer a entrada de questões defendidas por estes grupos na agenda governamental. Essa lógica de barganha se reproduz nos esforços de compor uma distribuição partidária e ideológica favorável no legislativo.

O último fenômeno do fluxo político que pode induzir a mudanças na agenda é a mudança de governo, ou no governo. Alterações no corpo pessoal das autoridades governamentais refletem em alterações nas prioridades e posicionamentos do governo. Os novos sujeitos trazem consigo novas percepções dos fenômenos sociais, outras interpretações de problemas e possíveis renovações nos cargos indicados, condições que produzem novos itens para comporem a agenda política de determinado tempo. Com a mudança de governo, ideias e propostas que antes não teriam espaço na agenda, se tornam políticas públicas em potência.

Mudanças efetivas na agenda, com o ingresso de novas pautas e a retirada de antigas (algumas podem ou não permanecer) se dão por um processo de convergência dos três fluxos (coupling). Cada fluxo independente, ou a mobilização de atores pontuais, não são suficientes para a abertura de janelas de oportunidades de formação da agenda. Apenas o conjunto desses processos, em um tempo e contexto específicos, de forma imprevisível ou programada, possibilitam alterações na agenda.

Vale ressaltar a diferenciação que Kingdon faz entre agenda governamental e agenda decisional: sendo a primeira constituída pelos eventos e contextos de mudança próprios dos fluxos de problemas e político, no qual há atenção do governo, mas sem proposições resolutivas; e a segunda, de caráter mais ativo e reduzido, apresenta também os efeitos do fluxo de soluções/alternativas, tendo seus problemas e assuntos contemplados próximos de uma decisão eminente por parte do presidente e sua cúpula. Ou seja, a agenda decisional é mais seleta, tem soluções acolhidas e integra a agenda 
governamental de problemas e questões mais amplas que estão sob atenção do poder público e atores correlatos.

\section{ESCOLA SEM PARTIDO: HISTÓRIA E SUA RELAÇÃO COM A FAMÍLIA BOLSONARO}

Miguel Nagib, assumido católico e conservador, começou a sua mobilização contrária ao que ele coloca como "doutrinação ideológica" nas escolas quando sua filha, a época em idade escolar, comentou que um professor havia comparado Che Guevara a Francisco de Assis. Sua narrativa é que tal episódio foi comprovação da tomada do sistema escolar brasileiro por forças marxistas, como parte de um grande projeto de controle da sociedade (PENNA; SALLES, 2017). Baseando-se no movimento estadunidense NoIndoctrination.org, que visava denunciar casos de doutrinação ocorridos no ensino superior, Nagib criou, em 2004, um site nomeado como "Escola sem Partido" e passou a receber e a divulgar denúncias de mesma natureza (MACEDO, 2018; PAULINO, 2018).

$\mathrm{O}$ site se consolidou e dele nasceu o movimento ESP, que veio a ganhar ressonância nacional apenas uma década após a criação do site. Antes de meados da década 2010, quando o movimento alçou reconhecimento, Nagib buscou criar alianças, difundir seus discursos sobre o problema da doutrinação nas escolas e propor novas e cada vez mais "refinadas" soluções para tal, de acordo com o clima que emergia na nação. Entre os anos de 2009 e 2013, o criador do ESP foi articulista e membro mantenedor do Instituto Millenium, importante think tank nacional focado na difusão das ideias de livre mercado e limitação do Estado. Neste período, Nagib pôde aproximar suas ideias antimarxistas a valores próprios de uma lógica neoliberal e privatista. Após as manifestações de 2013, com o fortalecimento de uma nova direita conservadora e antidemocrática na arena política nacional, o ESP aproximou-se também de outros elementos relevantes nessa emergente onda. Atrelando seu viés antimarxista no ensino e de valorização da liberdade econômica à militância religiosa fundamentalista inserida nas diversas esferas do Poder Legislativo, o ESP passou a ser ator de peso no cenário educativo brasileiro (DELCOURT, 2016; MIGUEL, 2016). 
A pauta antigênero e contrária à diversidade sexual se tornou principal frente de mobilização do ESP na política educacional. Por meio dela, o movimento se tornou grande força nacional na imposição de demandas conservadoras na política educativa, mostrando sua capacidade de articulação ao influenciar na retirada dos termos "gênero" e "sexualidade" do Plano Nacional de Educação (PNE) (2014-2024) e da Base Nacional Comum Curricular (BNCC) (REIS, 2016; MACEDO, 2017). A mobilização de embate ao trato de questões relativas a gênero e sexualidade se justifica pelos temores da "ideologia de gênero" que, em linhas gerais, representa a deturpação da perspectiva social de diferença entre os sexos. Segundo os que lutam contra a ideologia de gênero, ela seria um conjunto de ideias e práticas que visam destruir a ordem natural dos sexos, criada por deus, o que levaria à promiscuidade, homossexualidade, comunismo e o fim da civilização ocidental. O ESP soube capitanear muito bem o ascendente pânico moral social causado pelos receios à ideologia de gênero para catalisar suas ideias (MACHADO, 2018; MISKOLCI; CAMPANA, 2017).

Desde o início dos anos de 2010, o então deputado Jair Bolsonaro já discursava no Congresso contrariamente à ideologia de gênero "presente" em políticas governamentais da ex-presidente Dilma Rousseff, a exemplo do frustrado Programa Escola sem Homofobia, pejorativamente chamado de "kit gay" (BALIERO, 2018). Tais posicionamentos eram motivo de admiração e apoio por parte de Nagib, que endossava as ações de Bolsonaro em suas redes sociais digitais (ESPINOSA; QUEIROZ, 2017). O flerte ideológico somado ao crescimento do ESP no contexto das políticas educacionais no Brasil fez com que Bolsonaro, por meio de seus filhos, propusesse a Nagib a criação de um modelo de PL que congregasse os ideais defendidos pelo movimento, visando soluções para o fim da doutrinação e o instaurar de formas de controle dos docentes sobre o trato das temáticas de gênero e sexualidade. Os primeiros PLs sobre o "Programa Escola sem Partido" foram apresentados em 2014 por Flávio Bolsonaro e Carlos Bolsonaro, respectivamente na Assembleia Legislativa do Rio de Janeiro e na Câmara Municipal do Rio de Janeiro (MACHADO, 2018).

A eleição de 2018 foi capital para reforçar o entrelace destes dois atores no contexto político nacional. Para além das colocações de combate à doutrinação e sexualização precoce em seu plano de governo, Jair Bolsonaro passou boa parte de sua campanha presidencial divulgando falsas informações sobre o "kit gay" e seus impactos 
nocivos para as crianças nas escolas (ERNESTO, 2018). Como solução para o grande problema da doutrinação e da ideologia de gênero, Bolsonaro fazia constante defesa do ESP e de suas proposições. No único debate televisivo em que participou durante o período eleitoral, o candidato enfatizou a necessidade de o país ter um presidente que "honre e respeite a família, que trate com consideração criança em sala de aula, não admitindo ideologia de gênero, impondo a escola sem partido", fato comemorado e divulgado pelo ESP (ESCOLA SEM PARTIDO, 2018).

\section{ESCOLA SEM PARTIDO NA AGENDA EDUCACIONAL DO GOVERNO BOLSONARO?}

Em seu livro, Kingdon (2014) afirma que um ponto muito importante para a definição da agenda política se dá pelo envolvimento do presidente com determinada causa. $\mathrm{O}$ envolvimento transcende vagas menções em fóruns públicos ou compromissos firmados em campanha eleitoral. Para o cientista político, os demais atores presentes no processo para a elevação de uma condição a problema na agenda - e da subsequente passagem da agenda governamental para a decisional - buscam sinais mais pontuais e íntimos que evidenciem o comprometimento do presidente. Para o ESP, no decorrer do mandato do governo Bolsonaro (2019 - 2022), esse envolvimento não foi evidenciado. A percepção, por parte de Nagib, de certo distanciamento de Bolsonaro com as pautas defendidas pelo ESP se sustenta por decisões governamentais que vão de encontro, em um primeiro momento, com o avanço de suas proposições à agenda. Elemento importante para a construção desse cenário interpretativo é a indicação do corpo ministerial.

Taffarel e Neves (2019) sinalizam a existência de várias alas/frentes distintas dentro do governo Bolsonaro, com seus próprios interesses e objetivos, mas atuando em conjunto. Entre elas há a olavista (ligada à figura do guru Olavo de Carvalho); a militar; os econômicos-pragmáticos e; os evangélicos. Esses múltiplos atores refletiram seus interesses na barganha política pelas indicações aos ministérios. Como pontuam Mendonça e Moura (2019), a escolha para o primeiro representante da pasta de Educação se sucedeu a partir do embate entre alguns nomes: Guilherme Schelb, procurador da república ligado ao ESP e militante contrário à ideologia de gênero; Mozart Neves, professor universitário e representante do Instituto Ayrton Senna; Stavros Xanthopoulos, 
consultor ligado à Fundação Getúlio Vargas (FGV) e defensor da educação à distância (EAD) e; Ricardo Vélez, cristão, conservador e próximo ao Exército. Nagib também foi um dos nomes cotados pela mídia nacional para assumir a pasta (MASCARENHAS, 2018). Diante dos diversos interesses, condições, atores e recursos postos nesse processo definidor, Vélez foi escolhido como ministro.

Outro revés para o ESP foi a não indicação de Magno Malta, ex-senador capixaba e pastor evangélico, ao cargo de ministro da Mulher, da Família e dos Direitos Humanos. Malta foi o propositor do primeiro e único PL do ESP a figurar no Senado, o PL 193/2016, além de ser ator importante na rede de relações do movimento (PERONI; CAETANO; LIMA, 2017). Sua indicação era dada como certa, devido à proximidade do pastor com Bolsonaro e por ele não estar vinculado a nenhum cargo, já que perdera a reeleição para o Senado em 2018. Escândalos políticos o afastaram da chance de chefiar o ministério (AUDI, 2018). Com isso, a possibilidade do ESP de aproveitar a mudança de gestão para ascender à agenda foi reduzida, graças à não garantia de endossamento de suas pautas por parte de atores indicados pelo presidente.

No campo do legislativo nacional, o ESP teve certa mobilização. A deputada federal Bia Kicis foi propositora de um novo PL sobre o "Programa Escola sem Partido", o PL 246/2019, um dos primeiros a serem submetidos na nova legislatura. Kicis é cunhada de Nagib e antiga defensora das pautas do movimento. Ela teve papel relevante nas mobilizações populares pelo impeachment de Rousseff e foi uma das porta-vozes do movimento Revoltados Online em reunião com o ex-ministro da Educação do governo Temer, Mendonça Filho, na qual apresentaram as diretrizes do movimento ESP (ESPINOSA; QUEIROZ, 2017). O PL de Kicis, contudo, não avançou no primeiro ano da atual legislatura e não contou com pressão governamental para tal. A atuação do governo sobre as estruturas legislativas, em 2019, se focou no pressionar para a aprovação de reformas de cunho econômico, como a da previdência (MOTA; CALIXTO, 2019). No início de dezembro de 2019, o ex-presidente da Câmara dos Deputados, Rodrigo Maia (DEM-RJ) recriou a comissão especial, que havia sido encerrada ao final da legislatura anterior, destinada para a votação do PL 7180/2014 do ex-deputado Erivelton Santana, um dos primeiros ligados ao ESP no Congresso Nacional. O PL 246/2019 tramita em conjunto com o de 2014 (SIQUEIRA, 2019). Segundo Maia, tal medida se deu para atender pedidos de alguns parlamentares - sem menção a pressões governamentais -, mas 
que não havia compromisso com essa votação, e acrescentou que "existe o direito de existir o debate", em evidente discordância com as proposições dos PLs (CALGARO, 2019). Mesmo com a ascendência de Arthur Lira (PP-AL), aliado de Bolsonaro, à presidência da Câmara dos Deputados em 2021, os PLs sobre o ESP não avançaram nacionalmente.

O favorecimento ao debate relativo a questões econômicas, em detrimento de pautas moralizantes para a educação, em 2019, pôde refletir uma mudança no humor nacional. Durante o período eleitoral, a grande mobilização da campanha de Bolsonaro se deu pela disseminação de denúncias falsas a respeito do "kit gay" e da ideologia de gênero, na consolidação de um pânico social, o que poderia indicar certa percepção, por parte dos formuladores de políticas e atores próximos, assim como da mídia, de um clima nacional favorável à entrada de propostas moralistas e conservadoras na agenda. Contudo estas foram relegadas ao segundo plano, diante do clamor pelas pautas econômicas.

Desde o começo do novo mandado presidencial, o ESP se manifestou diversas vezes para evidenciar que ações do governo Bolsonaro não estavam sendo efetivas para combater o "petismo" e a doutrinação na educação nacional. Até meados de 2019, o ESP denunciava que o ministério da Educação (MEC) não sinalizava o combate à doutrinação e ideologia de gênero nas escolas em plano de ação ministerial. Também enfatizava a inoperância de Bolsonaro em criar comissão para investigar propaganda ideológica e partidária em ambiente escolar (ESCOLA SEM PARTIDO, 2019a; d). No dia 16 de julho de 2019, o ESP publicou em suas redes sociais que encerraria suas atividades:

\footnotetext{
Por absoluta falta de apoio, suspenderemos nossas atividades neste perfil a partir de $1^{\circ}$ de agosto. Daí p/frente, denúncias, pedidos de socorro e orientação deverão ser dirigidos ao MEC, secretarias de educação, Ministério Público e políticos q se elegeram com a bandeira do ESP. (ESCOLA SEM PARTIDO, 2019e).
}

Segundo Nagib, após as eleições de 2018, o ESP "saiu do radar" do presidente Bolsonaro. Não houve nenhuma mobilização do governo no intento de demonstrar o compromisso com as pautas do ESP, o que impediria o movimento de avançar no cenário político. O advogado ainda afirmou que tentou entrar em contato com o ministro Vélez por diversas vezes, mas não obteve êxito. Após a substituição deste por Abraham Weintraub, Nagib conseguiu marcar uma reunião pelo intermédio de Bia Kicis, mas 
novamente sem sucesso, o líder do movimento não teve garantia de compromisso, apoio e acolhimento do ESP por parte do governo em sua agenda. A falta de apoio político efetivo, que fosse além de discursos eleitorais, se somava a dificuldades de gerenciar e financiar as atividades do movimento, que é fortemente centralizado na figura de Nagib (SANTIAGO, 2018).

No anunciado dia de encerramento do ESP, $1^{\circ}$ de agosto de 2019, foi publicado em suas redes sociais que o movimento conseguiu recursos materiais necessários para continuar sua luta contra a doutrinação ideológica no ambiente escolar. De acordo com nota escrita por Nagib, alguns empresários foram "tocados pela Providência Divina" ao entenderem a importância da causa levantada pelo movimento e, assim, resolveram financiá-lo. Não há divulgação da lista de doadores e financiadores do movimento (ESCOLA SEM PARTIDO, 2019b).

A "volta” do ESP ao jogo das políticas educacionais no país é quase concomitante a uma mudança de postura do governo Bolsonaro em relação à defesa de pautas similares às promovidas pelo movimento. Ao final de setembro, Weintraub enviou ofício para as secretarias de educação estaduais e municipais, no qual dá orientações sobre a valorização do pluralismo de ideias, crenças e opiniões políticas e rechaça a doutrinação e o chamado bullying ideológico. O ex-ministro enfatizou que o nome do documento é "Escola para Todos" e que outras terminologias não se referem a essa ação governamental. O ministério disponibilizou canais de comunicação para a denúncia de casos extremos de violação ao que é preconizado no ofício (SALDAÑA, 2019; WEINTRAUB, 2019). E desde meados de novembro de 2019, a criação de um canal de denúncias para o ensino de temáticas que atentem à moral, religião e ética familiar de alunos também é foco de outra ação governamental, agora conjunta dos ministérios da Educação e da Mulher, da Família e dos Direitos Humanos (CANOFRE, 2019). A defesa ao pluralismo de ideias, o instaurar de formas de coerção à doutrinação, assim como a criação de canal de denúncias para casos de doutrinação nas escolas são importantes pontos de muitos PLs do ESP, como o PL 246/2019 (BRASIL, 2019).

As ações dos ministérios da Educação e da Mulher, da Família e dos Direitos Humanos estão em consonância com o discurso de Bolsonaro. Em dezembro de 2019, durante fala sobre aprovação de lei relativa ao ESP, o presidente afirmou que o governo já operacionaliza suas ações sobre a temática da doutrinação sem a necessidade de lei 
específica: “[...] já botamos isso sem lei. Já tem impresso em livros e cadernos o que o aluno tem direito. (Se) o professor quer falar que o PT é legal, então o aluno pode falar o contrário sem ser perseguido" (COSTA, 2019).

O início do ano de 2020 demarcou certas incongruências e confluências na conturbada relação entre o ESP e o governo Bolsonaro. No dia $1^{\circ}$ de janeiro, o ESP divulgou em seu Twitter que nada havia mudado na escola brasileira com a alteração da gestão federal, que continua sendo a "escola do PT" e tal realidade só seria alterada com a aplicação da "quimioterapia do ESP" (ESCOLA SEM PARTIDO, 2020d). No dia 8 de janeiro, foi realizada uma série de postagens no Twitter do ESP em que o movimento afirma que suas pautas são muito caras em períodos eleitorais, mas que são relegadas em outros momentos (ESCOLA SEM PARTIDO, 2020a; b). Nessas postagens também é sinalizado que 2020 foi ano eleitoral e, por tal motivo, políticos de direita voltariam a abordar a bandeira do ESP em seus discursos:

[...] 2020 é ano de eleições. Os políticos de direita provavelmente voltarão a falar em Escola sem Partido. Oportunismo? Não importa! O que importa é que, ao bater nesse tecla, eles contribuem p/conscientizar a população. Mas é pouco. Precisamos ir além. As sanguessugas ñ descansam (ESCOLA SEM PARTIDO, 2020b).

Nos dias 9 e 10 de janeiro de 2020, o ESP compartilhou postagens feitas pela deputada Bia Kicis em que, ao lado do ex-ministro Weintraub, buscam mobilizar a população para as pautas do ESP e endossam o apoio de Jair Bolsonaro e do ministro ao movimento (KICIS, 2020a; b). Contudo, no mesmo dia em que se deu a reunião entre Weintraub e Kicis, dia 9 de janeiro, o ex-ministro participou de uma coletiva de imprensa na qual sinaliza que o governo não adotaria uma linha de atuação tão incisiva contra a doutrinação. Weintraub afirmou que "[...] em vez de proibir a doutrinação, queremos garantir o direito das crianças a um ensino plural", e disse que gestão Bolsonaro procura uma "abordagem de pacificação" nas escolas (DESIDERI, 2020). Tanto no divulgar do encontro com Kicis, quanto na coletiva de imprensa, o ex-ministro enfatizou a ação do governo federal em relação ao ofício/programa "Escola para Todos" e a criação do canal de denúncias interministerial. 
Apesar de seu "renascimento" na segunda metade de 2019 e uma breve retomada de suas pautas no campo midiático em razão de estremecimentos com o governo federal, o ESP enquanto movimento teve pouquíssima relevância na política nacional em 2020. Em 21 de agosto daquele ano, o Supremo Tribunal Federal (STF) votou em plenário a constitucionalidade de cinco Leis vinculadas às propostas do ESP - uma estadual de Alagoas e quatro municipais de Nova Gama (GO), Foz do Iguaçu (PR), Ipatinga (MG) e Cascavel (PR) - que haviam sido aprovadas no decorrer dos anos de empreitadas legislativas do movimento. Todas as cinco foram julgadas inconstitucionais pela Corte (REIS, 2020).

Este julgamento se constituiu como um marco decisivo para a descontinuidade definitiva (até o momento) do ESP. Sem o apoio governamental, com o distanciamento progressivo de outras forças políticas em razão da indiferença de Bolsonaro e o solapar jurídico de sua principal frente de mobilização, o movimento ficou sem estruturas e redes de apoio para dar continuidade às suas ações. Em 22 de agosto de 2020, um dia após a decisão do STF, Nagib publicou a seguinte mensagem no Twitter do ESP: "Anuncio com tristeza o fim da minha participação no Movimento Escola sem Partido. Cessa, a partir de hoje, a atividade dos canais do ESP sob minha responsabilidade. Miguel Nagib" (ESCOLA SEM PARTIDO, 2020c). Após essa data não foram realizadas novas publicações nas contas do Twitter e site institucional do movimento. Os perfis do ESP nas redes sociais digitais Facebook, YouTube e Instagram foram excluídos.

O vácuo de informações produzidas pelo ESP após 22 de agosto de 2020 até o presente momento - 24 de dezembro de 2021 - reforça o papel central que Nagib tinha nas ações do movimento, bem como o não acesso do ESP enquanto organização à agenda decisional do governo Bolsonaro, apesar de suas pautas ainda ressoarem nas ações do governo e em sua base de apoio social.

\section{CONSIDERAÇÕES FINAIS}

Ao longo das explanações realizadas neste artigo, pode-se evidenciar, a partir da obra de Kingdon (2014), como se dá o processo de formação da agenda de políticas públicas. Alguns dos atores participantes, como o presidente, seus indicados e outros não 
governamentais tiveram suas formas de mobilização demonstradas. Também foram trabalhados os três fluxos que compõe a agenda, suas características, etapas e o fenômeno de convergência entre eles. Também foi possível demonstrar como o movimento ESP se consolidou enquanto ator relevante no cenário das políticas educacionais brasileiras na última década. E como se deram as interseções e fortalecimento recíproco entre a família Bolsonaro e o movimento, antes das eleições de 2018.

Por fim, a partir das informações levantadas pode-se afirmar que o movimento ESP não é ator com grande peso nos processos de delimitação da agenda governamental do mandato de Jair Bolsonaro. Apesar disso, suas interpretações a respeito de problemas sociais, assim como as soluções que coloca para estes são consideradas pelo governo, chegando à agenda decisional, como nos casos do canal de denúncias e do ofício "Escola para Todos", versões "maquiadas" dos PLs do movimento. Há uma tentativa do governo federal de, em certos momentos, dissociar suas ações da imagem do ESP, ao mesmo tempo em que o mantêm sob sua órbita para fins supostamente eleitorais. É importante ressaltar a dificuldade de separar pautas que são originadas pelo ESP das propostas por Bolsonaro - antes e depois de assumir a presidência - por muitas terem sido construídas em conjunto. E ao longo da escrita, percebeu-se a necessidade de estudos que contemplem correlações entre o ESP e períodos eleitorais, para um maior aprofundamento na temática.

\section{REFERÊNCIAS BIBLIOGRÁFICAS}

AUdi, A. A MÁGOA de MAgNo MALTA: 'EU ACHAVA QUE IA SER MINISTRO E EU NÃO FUI'. The Intercept Brasil, 05 dez. 2018. Disponível em: https://theintercept.com/2018/12/04/entrevista-magno-malta-dispensado-ministro/.

Acesso em: 02 dez. 2019.

BALIERO, F. "Não se meta com meus filhos": a construção do pânico moral da criança sob ameaça. Cad. Pagu, Campinas, n. 53, 2018.

Bolsonaro, J. O CAMINHo DA PROSPERIDAde: Proposta de Plano de Governo. 2018.2 Disponível em: http://divulgacandcontas.tse.jus.br/candidaturas/oficial/2018/BR/BR/2022802018/28000 0614517/proposta_1534284632231.pdf. Acesso em: 19 out. 2019.

BRASIL. Congresso. Câmara. Projeto de Lei 246, de 2019. Institui o "Programa Escola sem Partido”. Brasília, DF. 2019.

CALGARO, F. Rodrigo Maia recria comissão para discutir projeto Escola Sem Partido. G1, Brasília, 05 dez. 2019. Disponível em: 
https://g1.globo.com/politica/noticia/2019/12/05/rodrigo-maia-recria-comissao-paradiscutir-projeto-escola-sem-partido.ghtml. Acesso em: 10 jan. 2020.

CANOFRE, F. Damares anuncia canal de denúncias para questões contra moral, religião e ética nas escolas. Folha de São Paulo, Belo Horizonte, 19 nov. 2019. Disponível em: https://www1.folha.uol.com.br/cotidiano/2019/11/damares-anunciacanal-de-denuncias-para-questoes-contra-moral-religiao-e-etica-nasescolas.shtml?origin=folha. Acesso em: 02 dez. 2019.

CAPELLA, A. Formação da Agenda Governamental: Perspectivas Teóricas. In: Anais do XXIX Encontro Anual da ANPOCS. 2005, Caxambu, MG.

COSTA, R. Bolsonaro defende Weintraub e diz que Escola sem Partido está em operação. Estado de Minas, 18 dez. 2019. Disponível: https://www.em.com.br/app/noticia/politica/2019/12/18/interna_politica,1109094/bolso naro-defende-weintraub-e-escola-sem-partido-em-operacao.shtml. Acesso em: 10 jan. 2020.

DESIDERI, L. "Weintraub diz que 2019 marcou fim da "maldição do PT" na educação brasileira". Gazeta do Povo, Brasília, 09 jan. 2020. Disponível em: https://www.gazetadopovo.com.br/educacao/weintraub-diz-que-2019-marcou-fim-damaldicao-do-pt-na-educacao-brasileira/. Acesso em: 10 jan. 2020.

DELCOURT, L. Um TeaParty tropical: a ascensão de uma "nova direita" no Brasil. Lutas Sociais, São Paulo, v. 20 n. 36, p. 126-139, 2016.

ESCOLA SEM PARTIDO. 6/Infelizmente, a bandeira do ESP, tão útil na época das eleições, foi posta de lado. Por que? A doutrinação por acaso deixou de existir? Nada disso. A esquerda nunca investiu tanto na cooptação de estudantes como em 2019. Precisamos agir. 08 jan. 2020. Twitter: @escolasempartid. Disponível em: https://twitter.com/escolasempartid/status/1215034992130187264. Acesso em: 10 jan. 2020. a

ESCOLA SEM PARTIDO. 7/2020 é ano de eleições. Os políticos de direita provavelmente voltarão a falar em Escola sem Partido. Oportunismo? Não importa! O que importa é que, ao bater nesse tecla, eles contribuem p/conscientizar a população. Mas é pouco. Precisamos ir além. As sanguessugas ñ descansam. 08 jan. 2020. Twitter: @escolasempartid. Disponível em: https://twitter.com/escolasempartid/status/1215034993812094977. Acesso em: 10 jan. 2020. b

ESCOLA SEM PARTIDO. A PERGUNTA QUE NÃO QUER CALAR Por que o MEC do Presidente @ jairbolsonaro ainda não criou uma comissão para investigar o uso criminoso das escolas e universidades para fins de propaganda ideológica, política e partidária nos últimos 30 anos?. 12 jul. 2019. Twitter: @escolasempartid. Disponível em: https://twitter.com/escolasempartid/status/1149866516235661312. Acesso em: 02 dez. 2019. a 
ESCOLA SEM PARTIDO. Anuncio com tristeza o fim da minha participação no Movimento Escola sem Partido. Cessa, a partir de hoje, a atividade dos canais do ESP sob minha responsabilidade. Miguel Nagib. 22 ago. 2020. Twitter: @escolasempartid. Disponível

em: https://twitter.com/escolasempartid/status/1297221072262172672. Acesso em: 24 dez. 2020. c

ESCOLA SEM PARTIDO. Até agora, Jair Bolsonaro é o único candidato a Presidente da República a se comprometer publicamente com a aprovação do Escola sem Partido e o combate à ideologia de gênero. 10 ago. 2018. Twitter: @escolasempartid. Disponível em: https://twitter.com/escolasempartid/status/1028007495988600833. Acesso em: $02 \mathrm{dez}$. 2019.

ESCOLA SEM PARTIDO. Escola sem Partido segue firme, mais forte do que nunca. 01 ago. 2019. Twitter: @escolasempartid Disponível em: https://twitter.com/escolasempartid/status/1157097674740510725?s=20. Acesso em: 02 dez. 2019. b

ESCOLA SEM PARTIDO. Não caiam nessa mentira! A "Escola Atual" continua sendo a "Escola do PT". Nada mudou e nada vai mudar, enquanto a “quimioterapia” do ESP não for aplicada. 01 jan. 2020. Twitter: @ escolasempartid Disponível em: https://twitter.com/escolasempartid/status/1212386731162513408. Acesso em: 10 jan. 2020. d

ESCOLA SEM PARTIDO. Quem somos. Escola sem Partido. S/D. Disponível em: http://www.escolasempartido.org/quem-somos/. Acesso em: 19 out. 2019. c

ESCOLA SEM PARTIDO. Plano do MEC p/os próximos 3 anos e 5 meses ñ diz uma palavra s/combate à doutrinação e à ideologia de gênero nas escolas, promessa solene de @ jairbolsonaro na campanha. Atenção! Não se trata de cobrar o governo pelo q ainda $\tilde{\mathbf{n}}$ fez, mas pelo q ele diz q vai fazer daqui p/frente. 12 jul. 2019. Twitter: @escolasempartid.

Disponível

em: https://twitter.com/escolasempartid/status/1149683078333370368. Acesso em: 02 dez. 2019. d

ESCOLA SEM PARTIDO. Por absoluta falta de apoio, suspenderemos nossas atividades neste perfil a partir de $1^{\circ}$ de agosto. Daí p/frente, denúncias, pedidos de socorro e orientação deverão ser dirigidos ao MEC, secretarias de educação, Ministério Público e políticos q se elegeram com a bandeira do ESP. 16 jul. 2019. Twitter: @ escolasempartid.

Disponível em: https://twitter.com/escolasempartid/status/1151270755813994498. Acesso em: $02 \mathrm{dez}$. 2019. e

ESPINOSA, B; QUEIROZ, F. Breve análise sobre as redes do Escola sem Partido. In: FRIGOTTO, Gaudêncio. (Org.). Escola "Sem" Partido: Esfinge que ameaça a 
educação e a sociedade brasileira. Rio de Janeiro: Laboratório de Políticas Públicas da UERJ, 2017.

ERNESTO, M. Bolsonaro condena 'kit gay', tenta expor material na TV e é repreendido por William Bonner. Estado de Minas, Belo Horizonte, 28 ago. 2018. Disponível

em: https://www.em.com.br/app/noticia/politica/2018/08/28/interna_politica,984245/bolson aro-condena-kit-gay-tenta-expor-material-na-tv-e-e-repreendid.shtml. Acesso em: 02 dez. 2019.

KICIS, B. @AbrahamWeint reafirma seu apoio e do governo @ jairbolsonaro ao @ escolasempartid, o maior pesadelo da esquerda, nas palavras de José Dirceu. Vamos seguir trabalhando no Congresso e na sociedade, junto às famílias, para proteger as nossas crianças dos doutrinadores.. 10 jan. 2020. Twitter: @ Biakicis. Disponível em: https://twitter.com/Biakicis/status/1215608852567248897. Acesso em: 10 jan. 2020.

KICIS, B. Excelente encontro com o ministro @AbrahamWeint. Na pauta, @ escolasempartid, As mudanças no cenário da educação que vai ganhando novos rumos e sendo alavancada pelo governo @jairbolsonaro. Adeus índices negativos na nossa educação! Parabéns, ministro!. 09 jan. 2020. Twitter: @ Biakicis. Disponível em: https://twitter.com/Biakicis/status/1215324018787651585. Acesso em: 10 jan. 2020.

KINGDON, J. Agendas, Alternatives, and Public Policies. Pearson Education Limited, 2014.

MACEDO, E. As demandas conservadoras do movimento Escola Sem Partido e a Base Nacional Curricular Comum. Educ. Soc., Campinas, v. 38, nº 139, 2017, p. 507524.

MACEDO, E. Repolitizar o social e tomar de volta a liberdade. Educação em Revista, Belo Horizonte, v. 37, p. 1-15 2018.

MACHADO, M. O discurso cristão sobre a "ideologia de gênero". Rev. Estud. Fem. [online], vol. 26, n.2, p. 1-18, 2018.

MASCARENHAS, G. Procurador e líder do movimento Escola sem Partido cotados para a Educação. VEJA, 30 out. 2018. Disponível em: https://veja.abril.com.br/blog/radar/procurador-e-lider-do-movimento-escola-sempartido-cotados-para-a-educacao/. Acesso em: 08 nov. 2020.

MENCONÇA, A; MOURA, F. "IDEOLOGIA DE GÊNERO" E ESCOLA SEM PARTIDO: A AGENDA PRIVATIZANTE MORALIZADORA PARA A EDUCAÇÃO BRASILEIRA. Revista Artes de Educar, v. 5, n. 2, p. 201-222, 2019. 
MIGUEL, L. Da "doutrinação marxista" à "ideologia de gênero": Escola Sem Partido e as leis da mordaça no parlamento brasileiro. Direito \& Práxis, vol. 7, n. 3, p. 590-621, 2016.

MISKOLCI, R; CAMPANA, M. "Ideologia de Gênero": notas para a genealogia de um pânico sexual contemporâneo. Sociedade e Estado, vol. 32, p. 725-747, 2017.

MOTA, E; CALIXTO, L. Escola Sem Partido deve voltar à pauta após reforma da Previdência. Congresso em Foco, 14 set. 2019. Disponível em: https://congressoemfoco.uol.com.br/educacao/escola-sem-partido-deve-voltar-a-pautaapos-reforma-da-previdencia/. Acesso em: 02 dez. 2019.

PAULINO, C. O impulso neoliberal e neoconservador na educação brasileira: a imagem do "professor doutrinador" e o projeto "Escola sem Partido". Revista Educere Et Educare, vol. 13, n. 28, 2018.

PENNA, F; SALLES, D. A dupla certidão de nascimento do Escola Sem Partido: analisando as referências intelectuais de uma retórica reacionária. In: MUNIZ, A; LEAL, T (Orgs.). Arquivos, documentos e ensino de história: desafios contemporâneos. Fortaleza: EdUECE, 2017. p. 13-38.

PERONI, V; CAETANO, M; LIMA, P. Reformas educacionais de hoje: as implicações para a democracia. Revista Retratos da Escola, Brasília, v. 11, n. 21, p. 415-432, 2017. REIS, T. Gênero e LGBTfobia na educação. In: A ideologia do movimento Escola Sem Partido: 20 autores desmontam o discurso. São Paulo: Ação Educativa, 2016.

REIS, T. O iluminismo venceu o obscurantismo: STF enterra escola sem partido. Congresso em Foco, 24 ago. 2020. Disponível em: https://congressoemfoco.uol.com.br/opiniao/colunas/o-iluminismo-venceu-oobscurantismo-stf-enterra-escola-sem-partido/. Acesso em: 08 nov. 20020.

SALDAÑA, P. Weintraub manda ofício para redes de ensino que retoma diretrizes do Escola sem Partido. Folha de São Paulo, 23 set. 2019. Disponível em: https://www1.folha.uol.com.br/educacao/2019/09/weintraub-manda-oficio-para-redesde-ensino-que-retoma-diretrizes-do-escola-sem-partido.shtml. Acesso em: 02 dez. 2019.

SANTIAGO, A. Escola Sem Partido critica falta de apoio de Bolsonaro e suspende defesa da causa. Gazeta do Povo, 18 jul. 2019. Disponível em: https://www.gazetadopovo.com.br/educacao/escola-sem-partido-critica-falta-de-apoiode-bolsonaro-e-suspende-defesa-da-causa/?fbclid=IwAR3jDkEeM1iJa2emUm7LlBZBtXIsGTqSCd05fbYS_hj0KMJR-s8UPp-sJc. Acesso em: 02 dez. 2019.

SIQUEIRA, C. Câmara recria comissão especial para analisar Escola sem Partido. Câmara dos Deputados, 04 dez. 2019. Disponível em: https://www.camara.leg.br/noticias/622186-camara-recria-comissao-especial-paraanalisar-escola-sem-partido/. Acesso em: 10 jan. 2020. 
TAFFAREL, C; NEVES, M. TENDÊNCIAS DA EDUCAÇÃo FRENTE À CORRELAÇÃ̃O DE FORÇAS NA LUTA DE CLASSES: uma análise do governo Bolsonaro na perspectiva educacional. Estudos IAT, vol. 4, n. 2, p.310-329, 2019.

WEINTRAUB, A. Assinamos o ESCOLA PARA TODOS! As crianças têm direito a uma escola plural, sem doutrinação, onde haja respeito entre aluno e professor. Um ambiente sem bullying político, cultural ou religioso. 23 set. 2019. Twitter: @ AbrahamWeint. Disponível em: https://twitter.com/AbrahamWeint/status/1176304336663732224. Acesso em: 02 dez. 2019. 